\title{
Memória da ditadura em Caio Fernando Abreu e Luís Fernando Veríssimo
}

Jaime Ginzburg I USP

Resumo: Este estudo pretende examinar imagens referentes ao impacto da ditadura militar na sociedade brasileira em um conto de Caio Fernando Abreu, Os sobreviventes, e uma crônica de Luís Fernando Veríssimo, Lixo. A comparação entre os dois textos é examinada tendo em vista as noçôes de tragicidade e humor, para discutir modos de elaboração formal de referências à violência do periodo.

Palavras-chave: Caio Fernando Abreu, Luís Fernando Verissimo, ditadura militar.

Este trabalho procura pensar como encontramos em textos da literatura brasileira elementos referentes à necessidade de repensar a memória da ditadura militar no Brasil, e inclui três partes. As duas primeiras se dedicam a dois exemplos, referentes a diferentes momentos, 1982 e 1995, em que escritores de ficção centraram esforços sobre o tema. Na terceira, serão apresentadas algumas anotações teóricas resultantes da aproximação entre os dois textos, tentando delimitar problemas conceituais referentes ao assunto.

A memória da ditadura militar brasileira se impõe como um problema fundamental para a crítica literária. Em um país em que as heranças conservadoras 
são monumentais, e as dificuldades para esclarecer o passado são consolidadas e reforçadas, o papel de escritores, cineastas, músicos, artistas plásticos, atores e dançarinos pode corresponder a uma necessidade histórica. Enquanto instituições e arquivos ainda encerram mistérios fundamentais sobre o passado recente, o pensamento criativo pode procurar modos de mediar o contato da sociedade consigo mesma, trazendo consciência responsável a respeito do que ocorreu.

À crítica literária, entre outras tarefas, cabe o discernimento entre as várias formas de produção cultural, para estabelecer critérios de relevância e valor. Sem excluir controvérsia e incerteza, o debate sobre esses critérios está longe de ser consensual. A crítica universitária se ocupou, até hoje, de modo espantosamente insuficiente das relações entre a literatura brasileira e a ditadura militar. Muitos fatores contribuíram para isso, incluindo a presença de ideologias autoritárias nas universidades (OLIVEIRA: 1983), a cooptação da elite intelectual pelo sistema de poder (MICELI: 2004), e a circulação de correntes críticas defensoras de análises literárias que desconsideram o contexto histórico (BOSI: 1992). Um fator de presença constante é a alegação, dentro da política de especialização do saber, de que a ditadura militar não é um assunto para a crítica literária. Os críticos deveriam, na linhagem que remonta, entre outros, a Afrânio Coutinho, distinguir o literário do social, e se ocupar de seu objeto de maneira autônoma (COUTINHO: 1975). Indo mais longe, textos literários referentes à ditadura militar estariam presos demais a seu contexto de origem, o que os destituiria de interesse artístico, havendo neles apenas valor documental.

Os textos escolhidos são o conto Os sobreviventes, de Caio Fernando Abreu (ABREU: 1982), publicado em 1982, e a crônica Lixo, de Luís Fernando Veríssimo, divulgada em 1995 (VERÍSSIMO: 1997).

\section{Os sobreviventes}

O conto Os sobreviventes apresenta dois personagens que vivenciaram a ditadura militar brasileira. Publicado em 1982, o texto se insere no interior do processo de transição do regime autoritário para a democracia. O percurso de narração se dá como vertigem. O foco narrativo desliza da voz de enunciação da personagem feminina para o personagem masculino, sem travessões ou avisos para nortear a leitura.

Acompanhamos, de modo difuso e dispersivo, a trajetória da personagem feminina na resistência ao regime, através de alguns momentos decisivos. Dentro desse percurso, ela foi conduzida a uma internação. 
eu te olhava entupida de mandrix e babava soluçando perdi minha alegria, anoiteci, roubaram minha esperança, enquanto você, solidário e positivo, apertava meu ombro com sua mão apesar de tudo viril repetindo reage, companheira, reage, a causa precisa dessa tua cabecinha privilegiada, teu potencial criativo, tua lucidez libertária, bababá bababá. As pessoas se transformavam em cadáveres decompostos à minha frente, minha pele era triste e suja, as noites não terminavam nunca, ninguém me tocava, mas eu reagi, despirei, e cadê a causa, cadê a luta, cadê o potencial criativo? (p.16)

O momento em que a protagonista recupera sua disposição para a luta política, depois de atravessar o inferno da política brasileira, estabelece uma desorientação de sua perspectiva. Embora recuperada, a personagem reconhece estar impotente com relação às possibilidades de transformação da sociedade. A palavra "companheira", que remete à linguagem de resistência de esquerda dos anos 70, aparece em circunstâncias de tentativa de sustentação, posterior a um colapso.

A imagem "As pessoas se transformavam em cadáveres decompostos à minha frente" expressa com intensidade o componente traumático do passado da personagem. Imagem abjeta, que projeta a destruição dos corpos pelo regime sobre os olhos dos leitores, e contribui para um efeito estético de choque e arrebatamento (KRISTEVA: 1980). O trecho recupera, por similaridade, a tensão inerente aos depoimentos registrados de sobreviventes do enclausuramento e da tortura. Além disso, por apresentar essa tensão no contexto de um mal-estar físico e emocional insuportável, aponta para as dificuldades de produzir um depoimento desse tipo.

Com "as noites não terminavam nunca", Caio traz, metaforicamente, um dos elementos profundos e instáveis do trauma das vítimas, a destruição das referências de tempo, das noções lógicas de anterioridade e regularidade. A sensação de infinito aqui se associa diretamente a um colapso da constituição do sujeito (VIÑAR: 1992). Com "cadê a causa, cadê a luta", a desorientação da protagonista se soma a uma vontade de mudança, a uma expectativa de resistência. A repetição da palavra "cadê" carrega a incerteza de expectativa de uma resposta que não vem.

1. Conforme, por exemplo, relatos expostos em: VASCONCELOS, 1998; COMISSÃO DE CIDADANIA E DIREITOS HUMANOS. Relatório Azul 1997, 1998. 
O confronto com a ditadura é elaborado, em Caio Fernando Abreu, como uma vontade de ser outro. Uma busca de alteridade, no sentido individual, com uma vontade de viver diferente, sentir e pensar diferente. E no sentido coletivo, com uma expectativa de ser parte de outro Brasil, de outra sociedade. Como explica Fernando Arenas, em Abreu a problematização da utopia política se desenvolve como utopia de alteridade (ARENAS: 2003). O impacto traumático da ditadura leva os personagens a uma percepção severa de sua própria constituição. Diante da percepção de que a vida não fazia sentido, diante dos cadáveres se decompondo, como levá-la a fazer sentido?

A enorme desproporção entre as forças em conflito, dois indivíduos de um lado, o Estado do outro, é fator de inquietação, configurando um impasse. Essa desproporção já era tema central em A rosa do povo de Carlos Drummond de Andrade, no tempo do Estado Novo. ${ }^{2}$ No início da década de 80 , ela se atualiza em Caio como dissolução do idealismo quanto à capacidade de resistência do indivíduo em um contexto hostil.

Fernando Arenas entende que, em Abreu e em outros importantes escritores, existe a consciência crítica de que o nacionalismo brasileiro, de origem romântica, freqüentemente se associa a valores excludentes e interesses patriarcais. A defesa do Estado e da modernização tiveram historicamente convergência com o reforço da pobreza e da desigualdade.

Em resposta a esses impasses, surgem ao longo do século XX utopias libertárias referentes ao lugar do corpo na sociedade. A protagonista do conto, de acordo com essa perspectiva, diz tentar, através da experiência corporal, uma libertação do mal interiorizado pela agonia histórica. O sexo, a dança, a macrobiótica e os patins não são, no entanto, suficientes. Nem drogas, ecologia ou acupuntura - "sobrou só esse nó no peito, agora o que faço?"

O conto encerra expondo o esvaziamento do desejo dos personagens. Não há nenhum objeto capaz de trazer satisfação, garantir prazer, dotar a vida de sentido. Por isso os votos em "acreditar", uma vontade de querer, vontade de ter o que querer, "que leve para longe da minha boca esse gosto podre de fracasso" (p. 17).

Em larga medida, a concepção do conto corresponde à caracterização proposta por Idelber Avelar para a literatura pós-ditatorial latino-americana. O texto se desenvolve em torno das ruínas da ditadura, permitindo uma leitura alegórica (AVELAR: 1999). Os sobreviventes propõe uma imagem negativa e corroída do

2. Conforme SIMON, 1978; CAMILO, 2001. 
país, em contraste ostensivo com o nacionalismo ufanista dominante na propaganda de Estado dos anos 70.

Estilisticamente, chama a atenção um traço insistente da forma do conto. Trata-se do emprego da parataxe. É uma prosa marcada por enumerações e paralelismos. A função crítica da parataxe é muito importante (ADORNO: 1975). A sintaxe subordinativa se associa a uma capacidade de compreensão hierárquica, organizada e rigorosa da experiência. A opção da narrativa pelo privilégio da sintaxe coordenativa deixa elementos independentes uns com relação aos outros. É uma visão de mundo em mosaico, em caleidoscópio, que não se submete à lógica da causalidade e da seqüência linear.

Um foco narrativo aberto a indeterminações e uma sintaxe com ênfase na coordenação, em detrimento da subordinação, contribuem para configurar uma percepção fragmentária e descontínua da experiência, em articulação com a dimensão traumática do passado a ser exposto. ${ }^{3}$ A adequação entre tema e forma no conto chama a atenção quando levamos em conta suas condições de produção. Abreu encontrou um caminho criativo produtivo para interiorizar o antagonismo entre indivíduo e sociedade, e a crítica das imagens dominantes do Brasil.

\section{Lixo}

A crônica de Luís Fernando Veríssimo, Lixo, de 18/7/1995, propõe uma abordagem do passado ditatoral com emprego do registro cômico.

As pessoas que nos advertem contra "remoer"o passado tratam o passado como lixo. Mexer no passado só traz maus cheiros e coisas inúteis. O passado é o presente metabolizado e deixado para trás como resto, se tivéssemos o bom senso de outras espécies o enterraríamos. O jovem fascista de hoje vive em meio a velhos símbolos e velhos heróis, mas também considera o passado um lixo, para ser depurado da mentira dos outros e reciclado para novo uso. Pois.outra propriedade do passado como matéria orgânica é que ele é instável, mudando de significado a cada hora. Cada vez mais o historiador é um laboratorista a tirar novas teses de velhos fatos e de detritos em decomposição. Documentos são degradáveis, lembranças pessoais são quase sempre versões convenientes, no fim a memória se volatiza como o fedor e o fato vira fóssil. O que

3. Conforme GRANOFSKY, 1995; HORVITZ, 2000. 
não desaparece, paradoxalmente, são os desaparecidos. Esses deixaram mães, viúvas, filhos, parentes e amigos inconformados, que querem não vingança mas um corpo com valor legal e um túmulo identificável. E, acima de tudo, que os que morreram não sejam arrolados como lixo, no qual não se deve mexer por uma noção peculiar de polidez.

Numa entrevista à TVCom, da RBS do Rio Grande do Sul, o Éfe Agá disse que queria me ver no seu lugar para tratar dos desaparecidos, já que não existem documentos, indícios ou provas nas Forças Armadas ou em qualquer órgão do governo sobre eles. O presidente usou uma figura de retórica, não é verdade que gostaria de me ver em seu lugar. Eu até que aceitaria, já que, segundo ele, governar o Brasil não é tão difícil quanto parece, o horário é bom, o dinheiro é razoável, viaja-se muito, janta-se com a Marília Gabriela e há sempre a possibilidade de poder demitir o Andrade Vieira, que deve ser uma sensação boa. Mas o presidente estava apenas respondendo a um comentário que fiz aqui sobre o fato do esclarecimento do caso Rubens Paiva não estar entre suas prioridades pessoais, e agradeço a atenção e a educação. Só tem uma coisa, presidente. Indícios sobre os desaparecidos existem muitos, e a falta de documentos e provas é que pede uma determinação executiva. Com documentos e provas até eu.

O texto começa com uma reflexão teórica sobre a elaboração de imagens do passado. No seu início, é estabelecida uma contrariedade em relação ao esforço conservador de não investigar o passado. A cadeia metafórica construída em torno da imagem do lixo propõe a crítica, com o emprego do procedimento retórico da ironia, da recusa em encarar o problema da interpretação do passado como componente decisivo na experiência social.

A alusão ao "jovem fascista" fortalece a provocação de que, no momento presente da escrita, o autoritarismo do passado permanece, o que estaria em concordância com as teses de Paulo Sergio Pinheiro (PINHEIRO: 1991) e Oscar Vilhena Vieira (VIEIRA: 1991), sobre sua continuidade na transição democrática. Além disso, a frase estabelece uma conexão entre a atualidade do fascismo e as heranças dos regimes repressivos da primeira metade do século XX.

A imagem incisiva do historiador se integra a uma seqüência de alusões a pontos de vista cínicos, em ampla circulação na sociedade brasileira. A facilidade com que as ideologias conservadoras tratam com desprezo a memória das vítimas do autoritarismo se associa à ameaçadora imagem da volatilidade. Em algumas poucas linhas, se apresenta um breve painel de mecanismos da política do 
esquecimento, ${ }^{4}$ em coerência com estratégias de redução da violência histórica a distorções e mentiras.

A discussão teórica cede, e o estilo muda a partir da referência aos desaparecidos. Não são abstratos "mães, viúvas, filhos, parentes e amigos inconformados". Diferentemente dos que negam a necessidade de refletir sobre o passado, estes são dotados de um querer, uma convicção. Seu interesse consiste em "um túmulo identificável", uma possibilidade de reconhecer concretamente o ente querido. Retirar do desaparecido a volatilidade, a distância abstrata, a ausência remota, e atribuir a ele uma existência: um corpo. O texto volta-se ironicamente sobre sua cadeia metafórica inicial. Se para alguns o passado é lixo, para os parentes dos desaparecidos não é, e a negação da história não se restringe apenas a um debate teórico. Trata-se de provocar a ação.

Depois da reflexão conceitual e do apelo pelos perdidos, o texto se encaminha para um debate político, mudando novamente a linha de composição estilística. O discurso passa a se centrar na figura do presidente Fernando Henrique Cardoso. Inicialmente, se refere a ele em terceira pessoa, mas depois passa a segunda, indicando que é a ele que o texto, afinal, se dirige.

O presidente teria afirmado não poder lidar com a questão dos desaparecidos, em razão de que "não existem documentos, indícios ou provas nas Forças Armadas ou em qualquer órgão do governo sobre eles”. A afirmativa é contundente, e deixaria impotentes os parentes e amigos. Como o texto foi escrito em período democrático, sua contundência se presta a serviço da continuidade dos interesses de silenciamento dos setores conservadores da sociedade, que mantêm inacessíveis ou dispersos arquivos e documentações com relação ao que ocorreu.

A perspectiva adotada pelo texto, apelando para o eufemismo e a insinuação, estabelece contigüidade entre a negação contundente do presidente da república e as condições do exercício de seu cargo. As observações referentes ao horário, ao pagamento, às viagens, a Marília Gabriela e Andrade Vieira apontam para uma vida política que privilegia o gozo. Está ausente a seriedade responsável esperada, em relação à gravidade da dor envolvendo parentes e amigos dos desaparecidos.

A culminância do procedimento crítico ocorre com o aparecimento da primeira pessoa do discurso, em seu encerramento. A crônica se desenvolve

4. Conforme RICHARD, 1999.

5. Conforme TELES, 2001. 
como arena para o confronto entre segunda e primeira pessoa do discurso, entre o interlocutor e o enunciador (conforme BAKHTIN: 1986). A polissemia do discurso ficcional permite que esse pronome pessoal seja lido em identificação autoral e biográfica, como sendo de fato Luís Fernando Veríssimo. Permite também, pelo poder semântico da dêixis, que cada leitor específico se veja subitamente projetado no pronome. ${ }^{6}$ A sugestão engenhosa é de que cada um de nós poderia assumir a posição de responsável pela mudança da imagem do passado, pelo trabalho de busca dos desaparecidos.

\section{Impasses}

Esses dois textos têm em comum sua contrariedade ao autoritarismo. Ambos cumprem com rigor a orientação especificada por Beatriz Sarlo, referente ao papel de resistência da literatura. Em um ambiente social e intelectual conservador, Caio Fernando Abreu e Luís Fernando Veríssimo escolheram enfrentar um campo difícil, a reflexão sobre a experiência violenta do passado recente. Em ambos os casos, não fizeram isso através da defesa de qualquer doutrina homogênea, mas valorizando formalmente a ambigüidade, a tensão discursiva, a irredutibilidade a uma verdade absoluta. Trata-se de uma oposição formal às estratégias de dominação dos discursos repressivos.

Sendo ambos textos curtos em prosa, foram produzidos com complexidade formal, distantes das rotinas estruturais ordenadas, constantes na tradição literária brasileira. No caso de Abreu, um importante fator de complexidade é a tragicidade.

A abordagem trágica é congruente com uma percepção negativa do Brasil, e com uma elaboração da narrativa a partir do ponto de vista de um sujeito que, vítima do colapso resultante da violência extrema e da repressão disciplinar, não consegue atribuir sentido à própria existência.

Uma percepção trágica levaria a perceber a vivência do passado como impasse que não pode ser solucionado (LESKY: 1971). Nesse caso, estaríamos distantes da tragédia clássica, em que o confronto entre deuses e homens levaria à percepção da finitude da vida terrena, e as ações de "caráter elevado" levariam

6. Conforme BENVENISTE, 1976

7. Conforme SARLO, 1991. 
o espectador à catarse. ${ }^{8}$ Diferentemente, estaríamos aqui diante de uma configuração trágica sem transcendência, em que os embates se dão entre os próprios homens . Tragédia de homens desencantados, sem deuses e sem grandezas (VECCHI: 2003). A protagonista do conto se move no desencanto, tendo enfrentado a angústia de não poder sustentar seu idealismo quanto à capacidade de resistência.

A escolha de uma abordagem para configurar esteticamente os temas referentes à ditadura militar brasileira estabelece prioridades articuladas com um ponto de vista. A própria concepção de configuração estética define possibilidades para o entendimento do que aconteceu no passado histórico.

No caso de Veríssimo, aparece o cômico. Poderia uma mesma matéria histórica suscitar o olhar trágico e a piada? É possível compatibilizar humor e genocídio? Questões como essas se impõem para a crítica literária.

O humor de Veríssimo é empregado intensamente na crítica do cinismo. Essa crítica se volta, em um primeiro momento, contra os manipuladores do passado, e depois, contra o presidente Fernando Henrique Cardoso. Eufemismo e ironia se tornam instrumentos de provocação. A mescla de estilos, integrando o sério e o cômico, é conduzida em enfoque melancólico. É um humor com tremor de dentes, umedecido por espuma de raiva, espesso pela funda indignação que o motiva.

A escolha pelo humor implica em um grande perigo, o risco de redução da gravidade do assunto, com o desrespeito ao sofrimento das vítimas e de seus próximos. A crônica não escapa desse risco, e o humor é tanto sua estratégia de batalha como seu constrangimento.

Uma hipótese interpretativa que pode se voltar para ambos os casos consiste em recorrer à categoria do sinistro. A ambigüidade do sinistro se encontra, fundamentalmente, na associação entre o familiar e o estranho. O impacto traumático da ditadura militar se desdobra nos dois textos com essa ambigüidade. Há um componente familiar, pelo fato de que são evocadas experiências com as quais as vozes de enunciação se articulam diretamente; há, porém, um distanciamento. Em Os sobreviventes, há incertezas quanto a como atribuir sentido ao que foi vivido pela protagonista. Em Lixo, existe uma relação de confronto com as lacunas do passado, cujo entendimento não está ao alcance imediato. Os dois textos colocam em cena uma vivência que não está compreendida ou superada. O caráter individual das vozes de enunciação sustenta, metonimicamente, uma referência contextual à memória coletiva, que desconhece em vasta medida a si

8. ARISTÓTELES, 1987, p. 205. 
mesma. Freud associou a dificuldade cultural de lidar com os mortos à emergência do sinistro na literatura. É o impedimento da percepção, sugerido pelos olhos feridos, o emblema radical da presença do sinistro (FREUD: 1996).

A idéia de um passado que tem traços familiares e estranhos tem sua expressão precisa nas imagens do colapso da experiência do tempo. Sem tempo linear, não há como narrar uma estória com linearidade. A narrativa perde sua função explicativa, garantida pelas referências de causa e efeito, e assume um movimento interrogativo, voltado para indeterminações. A protagonista de Os sobreviventes, participante da resistência, lamenta que "as noites não terminavam nunca". É um conto sobre uma História ainda não contada. Sobre vozes não enunciadas.

Na crônica Lixo é formulada em escala hiperbólica a sujeição do passado à manipulação, relativizando critérios de verdade, ao mesmo tempo que aponta para, em meio ao mundo da distorção, a convicção de uma experiência que busca sua forma justa, na expectativa de resgate dos desaparecidos. Daí a necessidade de compor a crônica como arena, como espaço de luta de morte, desafio entre o escritor e o presidente, entre a literatura e o poder.

Os dois textos, cada um a seu modo, indicam um descompasso entre as condições disponíveis para atribuir sentido ao que ocorreu e as necessidades de quem foi atingido. Esse descompasso constitui um mal-estar quanto ao conhecimento, à idéia de verdade, à razão que embasa conceitos e percepções, recuando à posição para a qual, nos termos de Jeanne-Marie Gagnebin, "nunca deixará de existir a esfera obscura da matéria (...), a ambigüidade dos pensamentos e das falas", ${ }^{9}$ lugar da falha constitutiva, da impossibilidade de confiar nas instituições e nos discursos oficiais, em que o sinistro de Freud encontra o choque estudado por Walter Benjamin.

A conjunção de fragmentação narrativa, elementos sinistros e tragicidade afasta o conto de Abreu da tradição da representação. Não se trata de um reflexo realidade, mas de uma prosa sobressaltada, constituída por iluminações profanas, de inspiração surrealista (BENJAMIN: 1985), momentos de conhecimento assistemáticos e desestabilizadores.

A escolha por uma concepção tradicional de mimese ${ }^{10}$ implica uma organização formal do material a ser exposto. Ele deve estar unificado, articulado em tempo e espaço, de modo a permitir sua integibilidade. Uma representação da ditadura, no sentido mimético, pressupõe seu entendimento. Uma compreensão

9. GAGNEBIN: $2001 \mathrm{~m}$, p. 360 .

10. Conforme ARISTOTELes, 1987, p. 208. 
realista da ditadura levaria ao reconhecimento de uma imagem delimitada e compreendida. O leitor observaria na obra contornos de uma percepção cujos fundamentos conhece.

Contrariamente, uma ruptura com a tradição mimética poderia privilegiar uma estética voltada para o choque. Nesse caso, o objetivo não é que o leitor reconheça um universo anteriormente conhecido, mas que ele faça um esforço no sentido de relativizar seu conhecimento prévio, renunciar a seus pressupostos e encontrar na arte um percurso inovador de reflexão sobre o assunto abordado.

Nesse sentido, os dois textos têm a relevância de acentuar as incertezas sobre o que se passou, contribuindo com o esforço histórico de luta na política da memória. Mais do que a crônica de Veríssimo, o conto de Abreu alcança excelência nessa acentuação, chamando a atenção para o impacto da violência no corpo. A negatividade da forma é composta como dor que impregna a pele e a carne.

Abstract: This study tries to examine images referring to Brazilian military dictatorship, in Caio Fernando Abreu's Os sobreviventes and Luis Fernando Verissimo's Lixo. Comparing the two texts, we intend to discuss tragic and comic approaches to historical violence.

Key words: Caio Fernando Abreu, Luis Fernando Veríssimo, Brazilian dictatorship.

\section{Referências Bibliográficas}

ABREU, Caio Fernando. Morangos mofados. São Paulo: Brasiliense, 1982.

ADORNO, Theodor. Parataxis. In: Notas de literatura. Rio de Janeiro: Tempo Brasileiro, 1975.

ARENAS, Fernando. Utopias of otherness. Minneapolis: University of Minnesota, 2003. ARISTOTELES. Poética. In: Ética a Nicômaco; Poética. São Paulo: Nova Cultural, 1987.

AVELAR, Idelber. The untimely present. Durham: Duke University Press, 1999.

BAKHTIN, Mikhail. Marxismo e filosofia da linguagem. São Paulo: Hucitec, 1986. 
BENJAMIN, Walter. O surrealismo. In: Magia e técnica, arte e política. São Paulo: Brasiliense, 1985.

BENVENISTE, Emile. As relações de tempo no verbo francês. In: de lingüística geral. São Paulo: Nacional/EDUSP, 1976.

BOSI, Alfredo. Cultura brasileira e culturas brasileiras. In: colonização. São Paulo: Companhia das Letras, 1992. Problemas

CAMILO, Vagner. Drummond: da Rosa do Povo à Rosa das Trevas. São Paulo: Ateliê, 2001.

COMISSÃO DE CIDADANIA E DIREITOS HUMANOS. Relatório Azul 1997. Porto Alegre: Assembléia Legislativa, 1998.

COUTINHO, Afrânio. Da crítica e da nova crítica. Rio de Janeiro: Civilização Brasileira, 1975 .

FREUD, Sigmund. Lo siniestro. In: Obras completas. Madrid: Biblioteca Nueva, 1996. v. 3.

GAGNEBIN, Jeanne-Marie. Mimesis e crítica da representação em Walter Benjamin. In: DUARTE, Rodrigo; FIGUEIREDO, Virginia (Org.). Mimesis e expressão. Belo Horizonte: Editora UFMG, 2001. p. 360.

GRANOFSKY, Ronald. The trauma novel. New York: Peter Lang, 1995.

HORVITZ, Deborah. Literary trauma. New York: State University, 2000.

KRISTEVA, Julia. Pouvoirs de l horreur. Paris: Seuil, 1980.

LESKY, Albin. Do problema do trágico. In: A tragédia grega. São Paulo: Perspectiva, 1971.

MICELI, Sergio. Intelectuais à brasileira. São Paulo: Companhia das Letras, 2004.

OLIVEIRA, Betty Antunes de. O estado autoritário brasileiro e o ensino superior. São Paulo: Cortez / Autores Associados, 1983.

PINHEIRO, Paulo Sergio. Autoritarismo e transição. Revista USP. São Paulo, USP, n. 9, 1991.

RICHARD, Nelly. Políticas da memória e técnicas do esquecimento. In: MIRANDA, Wander Melo (Org.). Narrativas da modernidade. Belo Horizonte: Autêntica, 1999.

SARLO, Beatriz. Literatura y autoritarismo. In: MASSUH, Gabriela (Org.). Autoritarismo. Buenos Aires: Goethe Institut, 1991.

SIMON, Iumna Maria. Drummond: uma poética do risco. São Paulo: Ática, 1978.

TELES, Janaína (Org.). Mortos e desaparecidos políticos: reparação ou impunidade? São Paulo: Humanitas - USP, 2001.

VASCONCELOS, José Geraldo. Memórias do silêncio. Fortaleza: UFC, 1998.

VECCHI, Roberto. O que resta do trágico. In: ; FINAZZI-AGRO, Ettore (Org.). Formas e mediações do trágico moderno. São Paulo: Unimarco, 2003.

VERÍSSIMO, Luis Fernando. Novas comédias da vida pública. A versão dos afogados. Porto Alegre: L\&PM, 1997.

VIEIRA, Oscar Vilhena. Sociedade X Estado. Revista USP. São Paulo, USP, n. 9, 1991.

VIÑAR, Maren; VIÑAR, Marcelo. Exílio e tortura. São Paulo: Escuta, 1992. 